\title{
Emergencia de newsletters especializadas en Covid-19: información curada y actualizada en el email
}

\author{
The emergence of specialized \\ newsletters during Covid-19: curated \\ and up-to-date information in an email
}

\author{
Alba Silva-Rodríguez
}

Cómo citar este artículo:

Silva-Rodríguez, Alba (2021). "Emergencia de newsletters especializadas en Covid-19: información curada y actualizada en el email”. Profesional de la información, v. 30, n. 4, e300410.

https://doi.org/10.3145/epi.2021.jul.10

Artículo recibido el 11-02-2021

Aceptación definitiva: 11-06-2021

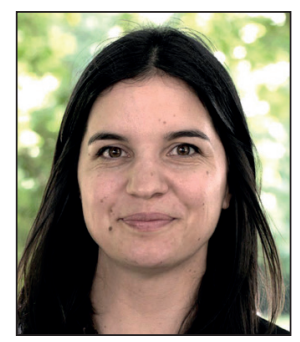

\section{Alba Silva-Rodríguez $\square$ \\ https://orcid.org/0000-0002-1221-5178}

Universidade de Santiago de Compostela

Facultade de Ciencias da Comunicación

Campus Norte, Avda. de Castelao, s/n

15782 Santiago de Compostela (A Coruña), España

alba.silva@usc.es

\section{Resumen}

En un contexto dominado por la sobreabundancia informativa y la multiplicidad de canales y plataformas se hace cada vez más importante la curación de contenidos. Los boletines, formato nacido aproximadamente hace 400 años, emergen y se mantienen como medios útiles para difundir noticias especializadas y personalizadas. En los últimos cuatro años se observa una tendencia al alza con relación a la proporción de usuarios que consumen newsletters y alertas informativas desde sus dispositivos móviles. Los editores buscan generar más tráfico directo a sus sitios web para retener suscriptores y atraer audiencia. El correo electrónico adquirió un importante valor desde que se decretó el estado de alarma a raíz de la pandemia mundial de la Covid-19. Diversos medios de comunicación crearon newsletters específicas sobre este tema resumiendo y actualizando diariamente las informaciones y los datos más relevantes sobre este acontecimiento. Este artículo analiza las newsletters especializadas en el tema del Covid-19 de cuatro medios internacionales de referencia: Eldiario.es (España), The New York Times (EUA), The guardian (Reino Unido) y Observador (Portugal). El análisis de contenido se complementa con la visión de cinco profesionales, expertos y académicos relacionados con el objeto de estudio. El objetivo consiste en valorar la importancia de este formato como nuevo modelo de negocio en un contexto de crisis, además de descubrir si este responde a la tendencia creciente del periodismo actual hacia la especialización y la personalización. Los resultados muestran que los medios utilizan los boletines especializados en Covid-19 con una finalidad informativo-estratégica, en donde priman las fuentes expertas y se vislumbra una estructura personalizada. Además, se trata de newsletters de autor que sirven como un canal excelente para promover la participación de los usuarios.

\section{Palabras clave}

Boletines; Coronavirus; Covid-19; Periodismo digital; Medios digitales; Curación de contenidos; Personalización; Especialización; Suscripciones; Análisis de contenido; Multimedialidad; Hipertextualidad; Interactividad. 


\begin{abstract}
In a world characterized by information overload and a multiplicity of channels and platforms, content curation is becoming increasingly important. First emerging approximately 400 years ago, newsletters remain a useful medium through which to disseminate specialized and personalized news. Over the last four years, an upward trend has been observed in the number of users who receive newsletters and informative alerts through their mobile devices. Publishers thus seek to drive more direct traffic to their websites to retain subscribers and attract an audience. Email communication acquired significant value after the state of alarm was declared as a result of the Covid-19 global pandemic. Various media outlets have created specific newsletters on this topic, summarizing and providing updates on the most relevant information and data on this subject on a daily basis. This article analyzes coronavirus-related newsletters from four leading international media: Eldiario.es (Spain), The New York Times (USA), The Guardian (UK), and Observador (Portugal). The content analysis is supported by the vision of five professionals, experts, and academics who have a connection with the topic of study. The aim is to assess the relevance of this format as a new business model in a context of crisis, in addition to analyzing how it relates to the growing trend in modern journalism towards specialization and personalization. The results reveal that the media use Covid-19-specialized newsletters with an informative-strategic purpose, where expert sources prevail and a personalized structure is apparent. Moreover, these are signature newsletters that work as excellent channels to promote user participation.
\end{abstract}

\title{
Keywords
}

Newsletters; Coronavirus; Covid-19; Digital journalism; Digital news media; Content curation; Personalization; Specialization; Subscriptions; Content analysis; Multimedia; Hypertextuality; Interactivity.

\section{Financiación}

Este trabajo se la llevado a cabo dentro del proyecto: Cibermedios nativos digitales en España: formatos narrativos y estrategia móvil, referencia RTI2018-093346-B-C33, financiado por el Ministerio de Ciencia, Innovación y Universidades y cofinanciado por el Fondo Europeo de Desarrollo Regional (Feder).

\section{Introducción}

El objetivo de esta investigación es analizar el impacto de los boletines o newsletters en el contexto de la pandemia sanitaria del coronavirus. Este tema ha despertado el interés de la comunidad investigadora desde el inicio de la crisis sanitaria (Casero-Ripollés, 2020; Lázaro-Rodríguez; Herrera-Viedma, 2020; López-Rico; González-Esteban; Hernández-Martínez, 2020; Moreno-Castro et al., 2020; Montaña-Blasco; Ollé; Lavilla-Raso, 2020).

A pesar de tener aproximadamente 400 años, los boletines no han desaparecido como medio útil para difundir el contenido de las noticias curadas al público. Rojas-Torrijos y González-Alba (2018) afirman que las newsletters pueden entenderse como un trabajo de curaduría de contenidos. Este tema ha sido tratado por Guallar y Codina (2018), que definen la curación de contenidos aplicada al periodismo como el conjunto de actividades basadas en la búsqueda, selección, análisis, verificación, gestión, edición y caracterización de informaciones publicadas en la Web con el propósito de producir o mejorar productos periodísticos, algo que implica su difusión a través de plataformas digitales. Díaz-Arias (2015) señala que la curaduría de contenidos puede servir para reconstruir el espacio público recogiendo las conversaciones generadas en los medios sociales.

Según el Digital news report del Reuters Institute publicado en 2016, los boletines responden a la tendencia creciente del periodismo hacia la especialización y a la personalización (Newman et al., 2016). Es lógico, por lo tanto, que constituyan un terreno para el estudio y la experimentación de técnicas encaminadas a generar un mayor grado de compromiso o engagement con la audiencia (Assmann; Diakopoulos, 2017).

La procedencia del término boletín se sitúa en el concepto italiano bolletino que, a su vez, se remonta al latín bulla (bola pequeña) (Apezarena, 2005, p. 26). En Francia reciben el nombre de feuilles confidentielles, presse privée, y a cada uno de los ejemplares se le denomina bulletin d'information o lettre d'information. Los anglosajones utilizan el término newsletter.

En la actualidad, las newsletters cobran nuevamente una importante significación. Una persona de cada seis accede semanalmente a noticias por correo electrónico (Newman et al., 2020a). En Bélgica este formato interactivo adquiere gran protagonismo y casi una cuarta parte de la población afirma que se trata de su principal fuente de noticias (Hendrickx; Donders; Picone, 2020). Si se observa el consumo entre países (Newman et al., 2020a) se pueden localizar diferencias significativas en relación con la audiencia de emails. En EUA las cifras -aunque

Las newsletters constituyen un terreno para el estudio y la experimentación de técnicas encaminadas a generar un mayor engagement con la audiencia 
más reducidas- son similares y una quinta parte $(21 \%)$ consulta noticias a través del correo electrónico. Sin embargo, en Corea del Sur (9\%), Reino Unido (9\%) o Suecia (10\%) la adopción decae notablemente. España ocupa una posición en la zona medio-baja, con un 15\%. Estas desigualdades probablemente tengan relación con la inversión y/ o promoción de este formato por parte de los principales medios de cada país. Además, en lugares como Sudáfrica (24\%), donde el ancho de banda es caro, los correos electrónicos pueden alzarse como una forma eficiente de distribuir noticias online.

Diversos autores evidencian el resurgimiento de las newsletters (Bucy, 2004; Mitchelstein; Boczkowski, 2010; Jack, 2016; Fagerlund, 2016; Newman et al., 2016). Las suscripciones a las mismas han aumentado recientemente debido a que cada vez más personas consumen información online. El éxito de este formato probablemente se explique gracias al contexto informativo actual, donde los ciudadanos buscan información actualizada e inmediata (Trilling; Schoenbach, 2015) pero no disponen de tiempo para pasar el día buscando o siguiendo las últimas novedades informativas. Guallar et al. (2021a) destacan su función de filtrado de contenidos frente a la superabundancia de "ruido" que existe en la Red. Fagerlund (2016) señala otro factor que influye en este aspecto y que tiene que ver con la expansión de los dispositivos móviles y con las altas cifras de adopción de esta tecnología. En este sentido, la aplicación de correo electrónico es una de las más consultadas por los usuarios de teléfonos inteligentes. En una era donde cada vez es más difícil llamar la atención de la audiencia, las compañías mediáticas necesitan poner sus miras allí donde se mueve su público. Núñez (2014) considera que las newsletters ofrecen mayores posibilidades de conversión que las publicaciones en redes sociales, además de ser más fáciles de segmentar y personalizar. Santos-Silva y Granado (2019) afirman que los boletines surgen como una oportunidad para interactuar con lectores, fragmentar contenido y como herramienta de empoderamiento para los periodistas. Además, las newsletters forman parte de un modelo de negocio que tiene el objetivo de construir conexiones directas con los consumidores para promover su lealtad.

Por otra parte, Twitter anunciaba el 26 de enero de 2021 la compra de Revue, una empresa que permite crear de una manera rápida y sencilla boletines editoriales con contenido creado por periodistas o medios de comunicación que quieran compartir sus trabajos y, a la vez, construir comunidades afines. Se percibe, por lo tanto, un incipiente interés en esta narrativa que poco a poco están adoptando los medios de comunicación. Sin embargo, pese a sus posibles ventajas, existen autores que se muestran críticos o escépticos respecto a la efectividad de los boletines (Brousssard; Floress, 2010). Otros se han preocupado por analizar los aspectos formales, estructurales y visuales de las newsletters llegando a la conclusión de que esta narrativa debe tener en cuenta ciertos aspectos del comportamiento del usuario para atraer la atención o la heurística visual (Kumar; Salo, 2016).

Tal y como apuntan Santos y Peixinho (2017) los boletines pueden concebirse como bits que organizan otros bits. Estructuran información que ya está disponible en otro lugar. A pesar de las ventajas que ofrece este formato para los medios (Fagerlund, 2016), como la oportunidad de mantener una relación directa con la audiencia, así como un alto grado de focalización, hay autores que consideran que el email crea situaciones de estrés y distracción que pueden llegar a reducir la productividad (Jack, 2016). De lo que no cabe duda es de que los boletines por correo electrónico han alterado la manera en que las personas reciben la información y se han convertido en un éxito para diversas organizaciones mediáticas como el Daily beast, Need2Know o theSkimm (Ha, 2016). En concreto, este último, se erigió como la primera aplicación periodística presente en dispositivos móviles. Quartz ha sido otro de los pioneros a nivel mundial a la hora de concebir una newsletter como un producto con valor editorial por sí mismo. Con su Daily brief reinventa este formato y lo convierte en un producto con una fuerza enorme partiendo de una estructura muy simple.

En España, El país lanzó el servicio de newsletters en 2015, con envíos durante la mañana y la tarde, resumiendo las noticias más importantes del día. Desde entonces, se ha convertido en uno de los principales canales de fidelización de la audiencia y en un medio excelente para conseguir un público fiel y potenciales usuarios.

Medios como el The New York Times o el Washington Post ofertan casi 70 newsletters que muestran el trabajo de varios departamentos y que están relacionadas con secciones diversas: negocios, tecnología, cultura, deporte, etc. Los correos electrónicos más exitosos consisten en productos editoriales creados por un periodista senior que aborda la información desde un tono informal y bajo un toque personal. The New York Times designó recientemente a David Leonhardt como el principal artífice de su newsletter matinal, que cuenta con más de 17 millones de suscriptores. En el Reino Unido, Matt Chorley desempeñó un papel similar durante seis años al cargo de Red box para The times, una mezcla entre política, humor e interacción con el usuario.

Por otra parte, también se desarrollan boletines emergentes con el objetivo de profundizar en una historia determinada de actualidad, como es el caso de la pandemia del coronavirus o las elecciones presidenciales en EUA, por ejemplo. Más allá de los correos electrónicos programados, un 73\% de los usuarios encuestados por Reuters (Newman et al., 2020a) afirma que se han registrado en algún boletín relacionado con un evento o tema específico o bien con una alerta de noticias de última hora. Estos emails pueden provenir de editores o de agregadores de noticias como Google News o Nuzzel. 
PROPORTION OF NEWSLETTER USERS THAT GET DIFFERENT TYPES OF EMAIL - SELECTED COUNTRIES

Newsletters that arrive at a regular time each day or each week

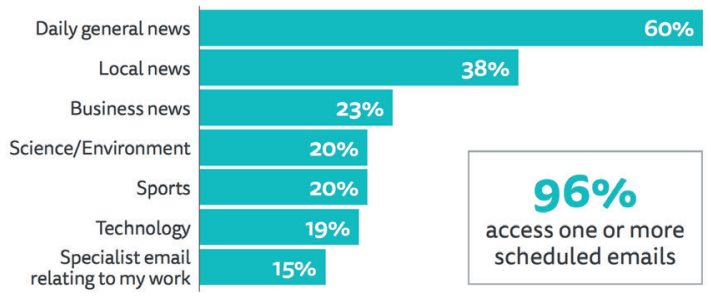

Alerts that arrive irregularly triggered by events

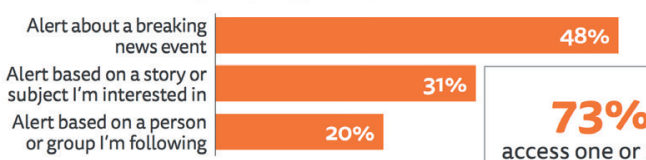

Q10b_EMAIL_TYPES_2020. You say you use email to access

alert based emails

news. Which of the following types of news emails do you get
sent? Please select all that apply. Base: Those who get news via email in USA, UK, Germany France, Italy, Spain, Ireland, Norway Sweden, Finland, Denmark, Belgium, Netherlands, Switzerland, Austria, pan, South Korea, Hong Kong, Australia, Canada, Argentina.

Gráfico 1. Porcentaje de usuarios de newsletters y alertas.

Fuente: Reuters Institute (Newman et al., 2020a)

\section{PROPORTION THAT USED A SMARTPHONE TO ACCESS NEWS IN THE LAST WEEK (2013-20) - SELECTED COUNTRIES}

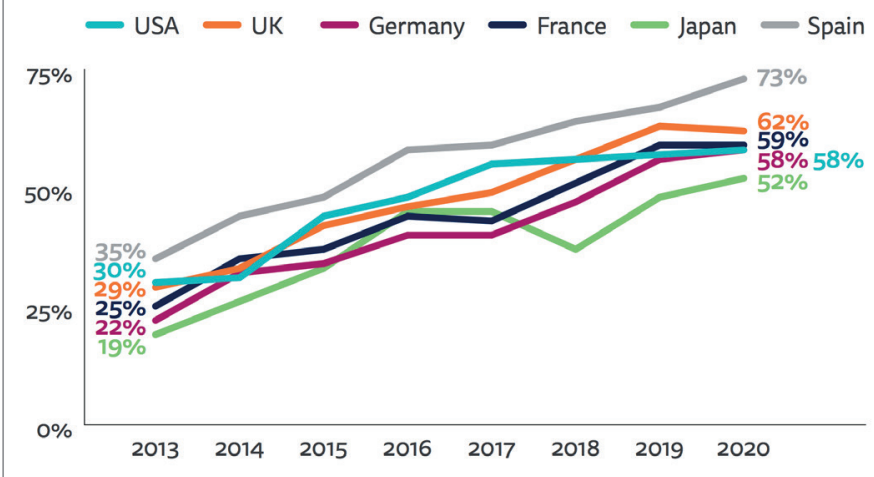

Q8b. Which, if any, of the following devices have you used to access news in the last week? Base: Total sample in each country $2013-20 \approx 2000$.

La epidemia por Covid-19 trajo consigo una apertura en lo que a muros de pago se refiere. Como indica García-Avilés (2021), la crisis sanitaria ha acentuado la crisis económica y los editores se ven en la necesidad de diversificar fuentes de ingresos y sistemas alternativos. Muchos diarios abrieron sus ediciones para que los lectores pudieran tener un acceso ilimitado a las coberturas sobre el coronavirus. Además, en algunos casos, han llegado a publicar sin costo sus ediciones impresas, tanto de periódicos como de revistas. Como consecuencia, el consumo informativo durante el mes de febrero experimentó un aumento sin precedentes y, según la consultora Comscore, los principales diarios digitales crecieron un promedio del 34\% respecto al mes anterior en usuarios únicos (Comscore, 2020).

\section{Materiales y método}

La investigadora McClaran (2017), que estudió el formato de la newsletter relacionándolo con la teoría de la agenda setting, apunta a que existe una falta general de investigación sobre este servicio de noticias dentro de la Comunicación. Esta idea es compartida por otros autores como Santos-Silva y Granado (2019), que afirman que existe una gran cantidad de bibliografía sobre el periodismo en el entorno digital pero que es residual la que aborda específicamente los boletines como nuevo formato y producto de la innovación mediática. Sin embargo, aunque todavía no hay una prolífica producción científica en este ámbito concreto, son reseñables los trabajos de Rojas-Torrijos y González-Alba (2018), Guallar et al. (2021a; 2021b) o Santos-Silva y Granado (2019).

Este trabajo tiene como objetivo, por lo tanto, contribuir a este campo de estudio mediante la evaluación y análisis de los boletines especializados en la temática del Covid-19 publicados por los principales medios tradicionales y nativos digitales de referencia internacional.

Los objetivos específicos de esta investigación son:

01. Examinar el impacto y emergencia del formato de newsletters en el contexto de crisis del coronavirus.

O2. Descubrir si el formato de newsletters responde a la tendencia creciente del periodismo actual hacia la especialización y la personalización.

O3. Determinar la función que cumplen los boletines en cada uno de los medios analizados.

04. Analizar el enfoque desde el que se aborda la temática del coronavirus en cada newsletter.

05. Detectar una estructura específica que permita situar las características de esta narrativa respecto al formato y a la organización de contenidos.

Para alcanzar los objetivos planteados se realiza un análisis de contenido, una técnica metodológica que tiene, en palabras de Krippendorff (2002) una orientación fundamentalmente empírica, exploratoria, vinculada a fenómenos reales y de finalidad predictiva.

Debido a la importancia de las newsletters para el periodismo como elemento catalizador de suscripciones de pago, se han seleccionado medios tradicionales de información generalista diaria y nativos digitales pertenecientes a tres escenarios diversos: 
- aquellos en los que el contenido de pago está más desarrollado y donde los consumidores muestran una disposición a pagar por el contenido, como es el caso de EUA (The New York Times) y Reino Unido (The guardian);

- los pertenecientes a mercados emergentes, como es el caso de Portugal (Observador);

- relacionados con escenarios inmaduros, o menos familiarizados con el pago de contenidos, como el de España (Eldiario.es).

También se han tenido en consideración los medios que alcanzaron unas mayores cotas de audiencia durante el período de la pandemia según los datos de la consultora Comscore, Google Analytics, Statista y los últimos informes del Reuters Institute (Newman et al., 2020a). Por último, se han valorado para la muestra los países en los que se evidencia un mayor consumo de información a través del correo electrónico.

En EUA se ha seleccionado The New York Times por ser el diario que ocupa, según la Federación Internacional de la Prensa Periódica, el primer puesto en cuanto a número de suscriptores digitales de pago (FIPP, 2019). Además, entre enero y marzo del 2020, el medio neoyorquino sumó alrededor de 587.000 nuevos lectores de pago en su edición online. A finales de abril contaba con más de cinco millones de suscriptores de sus productos digitales y más de seis millones de clientes si se le suman los registros al periódico impreso. Alcanzó estos datos en plena pandemia de la Covid-19 y a pesar de la decisión del periódico de ofrecer en abierto la mayor parte de los contenidos relacionados con el virus.

The Guardian, por su parte, se ha escogido por ser el medio británico que ofreció una mejor cobertura de la pandemia, según un estudio de la University of Oxford que analizó las actitudes de la población del Reino Unido durante el confinamiento (Newman et al., 2020b). Además, su web fue una de las fuentes más consultadas para leer información sobre la pandemia, solamente superada por BBC News.

En Portugal se ha optado por analizar el diario nativo digital Observador. Según las métricas de Google Analytics, ha sido uno de los medios más leídos durante la pandemia, llegando a alcanzar la cifra de 40 millones de visitas en su web durante el mes de marzo. Ha llegado a generar el mayor tráfico de su historia. Además, se trata de uno de los diarios que ha tomado la decisión de levantar la paywall de sus artículos Premium. Según el editor José Manuel Fernandes

"nuestra obligación como periodistas y como empresa es prestar un servicio público".

Eldiario.es ha sido, según Comscore, el más beneficiado de todos los medios durante la pandemia. Ha disparado sus visitantes un $61,8 \%$ hasta sumar un total de 15,7 millones. En febrero contabilizó 9,7 millones, por lo que ha sumado 6 millones más durante el último mes (Comscore, 2020).

Una vez detectado el universo de la muestra (gráfico 2) se seleccionaron los medios que disponían de un boletín gratuito especializado en noticias relacionadas con la cobertura de la pandemia. De esta manera, este artículo analiza las newsletters de cuatro diarios digitales:

- Eldiario.es (España);

- The New York Times (EUA);

- The Guardian (Reino Unido);

- Observador (Portugal).

El análisis se realizó entre la semana del 22 de mayo y la del 19 de junio de 2020. Se escogen los viernes siguiendo un criterio basado en la periodicidad en la que los medios publican las newsletters. Además, en aras de establecer un análisis comparativo, se selecciona este día por coincidir con la publicación del boletín semanal de The Guardian. La muestra queda conformada por 20 newsletters pertenecientes a los cuatro medios objeto de estudio. Para el análisis se tienen en cuenta las siguientes variables:

- Hipertextualidad

- Multimedialidad

- Interactividad

- Estructura

- Autoría

- Contenido principal.

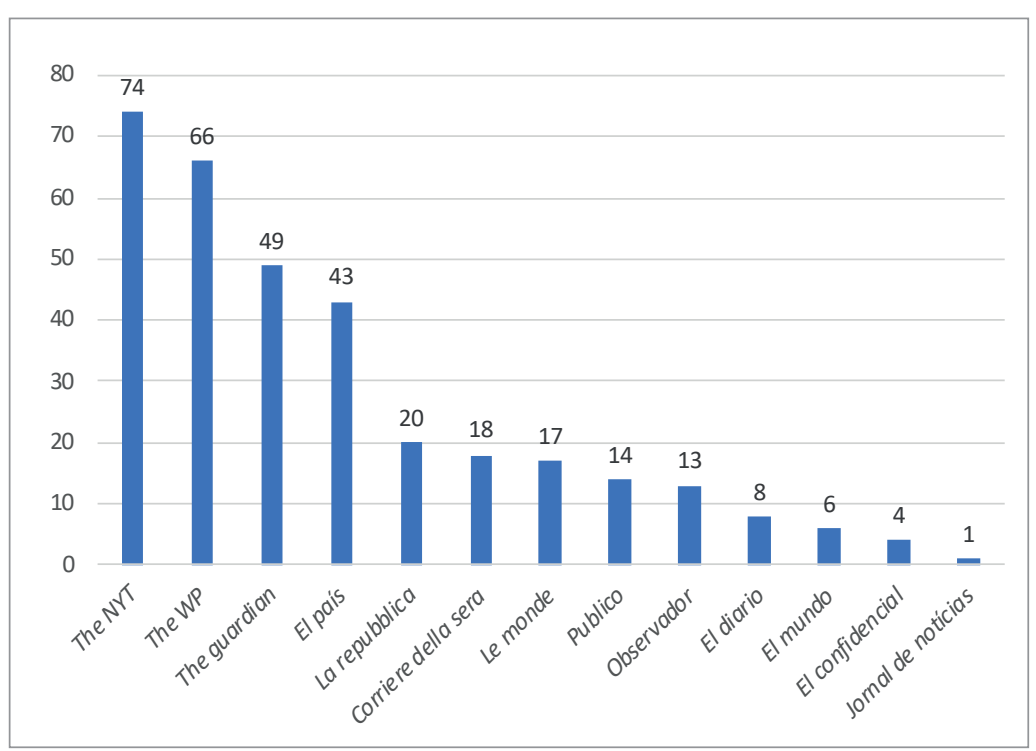

Gráfico 2. Número de newsletters editadas por los principales medios de referencia en EUA, España, Italia, Portugal y Francia. 
El análisis de contenido se realizó a partir de una base de datos creada en Excel.

El estudio empírico se complementa con la realización de cuestionarios autoadministrados por email (Bosch; Torrente, 1993). El proceso de selección de los entrevistados se dividió en dos fases. El 25 de mayo de 2020 se envió una primera solicitud de participación a través del correo electrónico a todos los responsables de las ediciones de los boletines de los medios analizados. Se hicieron recordatorios periódicos cada mes y medio, hasta el 25 de enero del 2021. Al no obtenerse ninguna respuesta se optó, entonces, por seleccionar a cinco investigadores, académicos y profesionales siguiendo un criterio determinado por el grado de conocimiento y relevancia investigadora sobre el tema. Se les proporcionó un cuestionario a través de correo electrónico y realizado en Google Docs entre la segunda y tercera semana de enero de 2021. La muestra quedó finalmente conformada por los siguientes profesionales:

- Josep-Lluís Micó, catedrático de Periodismo de la Universitat Ramon Llull (Barcelona, España).

- Marius Dragomir, director del Centro de Medios, Datos y Sociedad de la Universidad de Europa Central (Budapest, Hungría).

- Alfred Hermida, profesor y académico de la University of British Columbia (Vancouver, Canadá).

- Luís Antonio Santos, profesor y académico de la Universidade do Minho (Braga, Portugal).

- Kevin Young, director de audiencia y redes sociales de The economist (Londres, Reino Unido).

El cuestionario consta de dieciocho preguntas abiertas agrupadas en dos bloques:

- Modelos de negocio: tipo de ingresos que generan las newsletters, suscriptores y estrategias de fidelización de usuarios.

- Gestión de newsletters desde el punto de vista periodístico: perfiles profesionales, impacto en las rutinas periodísticas, aportes o ventajas de los boletines especializados, grados de innovación, finalidad o propósito y elementos interactivos y/o participativos.

\section{Resultados}

Se han analizado 20 newsletters gratuitas correspondientes a dos medios nativos digitales (Eldiario.es y Observador) y dos medios tradicionales (The Guardian y The New York Times). La pionera fue la del diario norteamericano, que nació el 2 de marzo del 2021.

En lo que respecta a la periodicidad, los cuatro medios analizados distribuyen sus boletines diariamente excepto The Guardian, que opta por un modelo de boletín semanal. Aunque las newsletters suelen enviarse por la mañana o al mediodía, el diario portugués es el único que se decanta por publicarlas en la franja nocturna, a las 22:00 pm.

Sobre el volumen de contenidos de los boletines analizados se observa que el medio que incorpora un mayor número de informaciones es Eldiario.es, con una media de 29 piezas en cada newsletter durante el período observado. Le siguen Observador (28), The New York Times (18) y The Guardian (5).

Tabla 1. Ficha identificativa de las newsletters analizadas

\begin{tabular}{|l|l|l|l|c|c|}
\hline \multicolumn{1}{|c|}{ Medio } & \multicolumn{1}{|c|}{ País } & \multicolumn{1}{|c|}{ Título de la newsletter } & \multicolumn{1}{c|}{ Periodicidad } & $\begin{array}{c}\text { Hora de } \\
\text { recepción }\end{array}$ \\
\hline Eldiario.es & España & Coronavirus: lo que debes saber hoy & Diaria matinal & $08: 00$ am & 11 de marzo \\
\hline The New York Times & EUA & Coronavirus briefing & Diaria matinal & $07: 00$ am & 2 de marzo \\
\hline The Guardian & Reino Unido & Coronavirus: the week explained & Semanal (viernes) & $14: 00$ pm & 18 de marzo \\
\hline Observador & Portugal & Coronavírus especial & Diaria nocturna & $22: 00$ pm \\
\hline
\end{tabular}

\section{Boletines especializados en Covid-19: casos de Eldiario.es, The New York Times, The Guardian y Observador}

A continuación, se presentan los hallazgos obtenidos después de analizar cada boletín identificando la estructura, contenidos principales, presencia de elementos multimedia, hipertextuales e interactivos y autoría.

\subsection{Boletín de Eldiario.es: Coronavirus: lo que debes saber hoy}

Eldiario.es dispone de un boletín titulado Coronavirus: lo que debes saber hoy firmado por la periodista María Ramírez. Se envía todos los días a primera hora de la mañana, a las 08:00 h, y su principal función es informar.

El boletín de Eldiario.es se presentó el 11 de marzo de 2020 con la etiqueta de "efímero" apuntando a que duraría "lo que dure la pandemia". El 19 de junio María Ramírez se despedía con una carta en la que agradecía el apoyo de las 17.000 personas suscritas al mismo (Ramírez, 2020) y destacaba el esfuerzo por cumplir con la función esencial de servicio público a través de esta newsletter especializada. A partir de ese momento, el boletín pasa a ser semanal, una tendencia que se repite en todos los medios analizados. 
Desde el punto de vista multimedia destaca el uso de imágenes y la ausencia, en general, de infografías, vídeos, audios y mapas. Sin embargo, aunque estos elementos no aparezcan reflejados en el propio email, gran parte de las informaciones destacadas en los boletines disponen de este tipo de recursos. Respecto a la hipertextualidad, presenta numerosos hipervínculos que dan acceso a informaciones del propio diario y de otros medios. En este sentido, el nativo digital Eldiario.es es el medio que hace un mayor uso de la interactividad a partir de enlaces y el que incorpora, a su vez, más fuentes externas al propio medio. Entre éstas, destacan las que provienen de organismos como el Ministerio de Sanidad - la Organización Mundial de la Salud, pero tienen especial relevancia las relacionadas con medios internacionales como el The New York Times, el Washington Post, The Guardian, The lancet, StatNews o TheCity. También se vinculan las informaciones a las webs de las principales plataformas de verificación, como Maldita o Newtral. Es además muy habitual localizar noticias que se relacionan con publicaciones científicas provenientes de universidades de prestigio como la de Harvard, por ejemplo.

Además, sobresale el carácter informal en lo que a redacción se refiere, abusando de la primera persona del singular, e invitando al lector a participar y/o aportar contenido. Tal es el caso de frases como la siguiente:

“Empiezo a recoger vuestras ideas para el nuevo mundo después de lo que estamos pasando. Os animo a que mandéis sugerencias concretas basadas en vuestra experiencia o conocimiento a salud@eldiario.es. Sobre transporte, convivencia, educación, rutinas diarias... lo concreto es bello".

La estructura del boletín es personalizada. Dispone de diferentes secciones que presentan un diseño cuidado a dos colores (blanco y verde) con gran presencia de emoticonos que le imprimen un carácter directo e informal. Un aspecto diferencial con respecto al resto de formatos analizados reside en la presencia del epígrafe "Algo bueno" con el fin de ofrecer algún punto positivo o esperanzador en el medio del maremágnum de noticias trágicas. Algunas de las informaciones relacionadas con esta sección tienen que ver con:

- los resultados de las investigaciones científicas que ayudan a conocer mejor el virus (sistema de análisis de las aguas fecales como método de vigilancia de la epidemia o los efectos de la dexametasona, que previene la muerte de una de cada ocho personas con respiradores);

- los datos positivos de la incidencia de la Covid-19 después del confinamiento (los bloqueos en Europa salvaron más de 3 millones de vidas);

- la eficiencia de determinados métodos de protección como las mascarillas (una peluquera infectada de coronavirus y con síntomas siguió acudiendo al trabajo y atendió a más de 100 clientes. Llevaba mascarilla y ninguna persona, aparte de la peluquera y un compañero, dieron positivo).

Se incluyen contenidos de autopromoción en determinadas ocasiones para publicitar el trabajo de compañeros con enlaces a la web del propio medio, como sucede en el siguiente ejemplo:

"Pero otras, por ejemplo, las empresas de call center, han metido prisa a sus empleados por volver a las oficinas, como cuenta nuestra reportera Laura Olías, experta en información laboral, aquí".

Otro aspecto interesante reside en la promoción de las voces femeninas del medio. En este sentido, María Ramírez promueve los contenidos creados por compañeras de Eldiario.es, entre las que se encuentra la médica Esther Samper. Belén Remacha, Natalia Chientaroli y Marta Borraz también ocupan un lugar destacado a la hora de promocionar el medio.
La personalización, la multimedialidad y la hipertextualidad son, a juicio de los expertos, los elementos más importantes a la hora de considerar un boletín 
Tabla 2. Estructura personalizada del boletín de Eldiario.es

\begin{tabular}{|c|c|c|}
\hline Secciones & Contenido & Ejemplo \\
\hline Introducción & $\begin{array}{l}\text { Párrafo de resumen de entre cuatro y seis líneas con } \\
\text { lo más importante del día. }\end{array}$ & $\begin{array}{l}\text { Un tercio de los infectados de coronavirus en España no tiene ni } \\
\text { ha tenido síntomas. El } 95 \% \text { de la población no lo ha contraído y } \\
\text { puede contagiarse, según la segunda oleada del estudio sobre la } \\
\text { presencia del virus en la población. }\end{array}$ \\
\hline Información & $\begin{array}{l}\text { Bajo el epígrafe "La tendencia" se resumen los datos } \\
\text { relacionados con el número de muertes y hospitaliza- } \\
\text { ciones por Covid-19 en España. }\end{array}$ & $\begin{array}{l}\text { La tendencia. Al menos otras } 52 \text { personas han muerto por coro- } \\
\text { navirus en España y } 1.553 \text { han sido diagnosticadas en la última } \\
\text { semana, según la información publicada ayer por Sanidad con los } \\
\text { datos comunicados por las comunidades autónomas. } 89 \text { personas } \\
\text { han necesitado hospitalización en los últimos siete días, pero baja } \\
\text { el número de personas en cuidados intensivos. Hace tres semanas, } \\
\text { había más de } 600 \text {; según los datos de ayer, eran } 321 \text {. }\end{array}$ \\
\hline $\begin{array}{l}\text { Anécdotas inter- } \\
\text { nacional }\end{array}$ & $\begin{array}{l}\text { Párrafos breves que explican datos relevantes rela- } \\
\text { cionados con la incidencia de la Covid-19 en distintos } \\
\text { países. Suelen ir acompañados de emoticonos con las } \\
\text { banderas de los países. }\end{array}$ & $\begin{array}{l}\text { Otro brote en Alemania. Los } 700 \text { habitantes de un bloque de apar- } \\
\text { tamentos de Gotinga, en el centro del país, están aislados por al } \\
\text { menos un centenar de contagios de coronavirus. Este brote sigue } \\
\text { a otro en siete bloques de viviendas de Berlín y otro en una planta } \\
\text { cárnica en Gütersloh, en el noroeste del país. }\end{array}$ \\
\hline Ciencia & $\begin{array}{l}\text { Este epígrafe tiene una gran relevancia en el boletín. } \\
\text { Consiste en resumir hallazgos importantes de inves- } \\
\text { tigadores. }\end{array}$ & $\begin{array}{l}\text { Las gotas que contienen virus permanecen más tiempo en el } \\
\text { aire de habitaciones poco ventiladas, secas y calurosas, según } \\
\text { un estudio de investigadores holandeses publicado en la revista } \\
\text { científica The lancet. }\end{array}$ \\
\hline Información & $\begin{array}{l}\text { Bajo la etiqueta "Las cifras" se indica el dato principal } \\
\text { de casos confirmados en España según la información } \\
\text { facilitada por el Ministerio de Sanidad. }\end{array}$ & $\begin{array}{l}\text { Las cifras } \\
245.268 \text { casos confirmados }\end{array}$ \\
\hline $\begin{array}{l}\text { Participación } \\
\text { de la audiencia }\end{array}$ & $\begin{array}{l}\text { Espacio reservado a la participación e interacción } \\
\text { de los usuarios. La autora de la newsletter invita a los } \\
\text { lectores a que envíen sugerencias relacionadas con } \\
\text { diversas áreas. Los comentarios de la audiencia se } \\
\text { publican y se integran en las newsletters. }\end{array}$ & $\begin{array}{l}\text { José María de Córdoba nos propone una idea para favorecer a los } \\
\text { peatones. } \\
\text { "Poner en grandes avenidas plataformas para andar más rápido, } \\
\text { tipo las de los aeropuertos, cubiertas por encima con placas } \\
\text { solares. A la vez que servirían para la protección del sol y la lluvia, } \\
\text { servirían para la alimentación de las plataformas". }\end{array}$ \\
\hline $\begin{array}{l}\text { Funcional: } \\
\text { Las respuestas } \\
\text { que tenemos }\end{array}$ & $\begin{array}{l}\text { Lista de recursos con guías elaboradas por Eldiario.es y } \\
\text { otros medios que pueden ser útiles para los usua- } \\
\text { rios. La sección lleva el título de "Las respuestas que } \\
\text { tenemos". }\end{array}$ & $\begin{array}{l}\text { 1. La enfermedad y sus síntomas } \\
\text { - Nuestra pieza con las dudas básicas sobre síntomas y precau- } \\
\text { ciones básicas. } \\
\text { - La guía de la Escuela de Medicina de la Harvard University. Si te } \\
\text { hace falta, la puedes traducir con Google Translate. } \\
\text { - La guía de Maldita.es de los bulos sobre el coronavirus } \\
\text { - ¿Dónde llamar si tienes síntomas? Aquí está el enlace del Minis- } \\
\text { terio de Sanidad con los teléfonos según donde estés. } \\
\text { - ¿Y por WhatsApp? Sanidad también tiene un canal de informa- } \\
\text { ción por WhatsApp. Basta guardar el número +34 } 600802802 \\
\text { en los contactos del teléfono y escribir la palabra “hola" para } \\
\text { empezar la conversación. }\end{array}$ \\
\hline
\end{tabular}

\subsection{Boletín de The New York Times: Coronavirus briefing}

El diario norteamericano lanzó su newsletter especializada en la crisis sanitaria el 2 de marzo de 2020. Cuando surgieron los primeros casos de coronavirus en Wuhan (China) a finales de diciembre, el editor Michael Slackman de The New York Times consideró necesario realizar una sesión informativa diaria en vivo que sirviera como guía actualizada. Posteriormente publicó Coronavirus briefing, un boletín para informar y poner en contexto las noticias de la pandemia. En la primera edición se constataba que esta narrativa serviría también para ayudar a mantener la seguridad de la comunidad. TNYT publicó ya en su informe de innovación de 2014 que los boletines serían su nueva estrategia informativa (Santos-Silva; Granado, 2019).

La newsletter de The New York Times es de autor, aunque no siempre la firma la misma persona. En este caso, colaboran varios periodistas como Melina Delkic, Andrea Kannapell, Adam Pasick, Lara Takenaga, Tom Wright-Piersanti y Patrick J. Lyons.

De los medios analizados, es el que mejor aprovecha las posibilidades multimedia e interactivas en la información enviada por correo electrónico. Destaca la estructura del boletín, que consiste en un mapa seguido de destacados y secciones de texto acompañadas de gráficos. Los recursos más utilizados son los mapas y las infografías. Dispone, además, de contenidos de autopromoción que se centran, principalmente, en la inclusión de enlaces a la web principal del medio y a las redes sociales. Nuevamente se localizan aspectos que determinan su propósito estratégico, para fidelizar a la audiencia, aunque su finalidad también es informativa. 
Coronavirus briefing destaca por presentar una estructura personalizada. Aunque austera en su diseño, con fondo blanco y texto en negro, suele incorporar elementos gráficos que le imprimen una estética más dinámica e interactiva. Además, la organización de contenidos sigue un mismo patrón en todas las ediciones con una introducción en la que se presentan los temas más importantes de la jornada seguida de bloques especializados (como opinión, ciencia e internacional) (tabla 3). El boletín finaliza con un apartado de soft news en el que se comparten informaciones de servicios (como el caso de los datos relacionados con las aperturas de movilidad o las recomendaciones). En este sentido, se detecta el interés del medio por ofrecer un servicio a la comunidad a través de contenido útil y contextualizado.

Por último, al igual que sucedía con el nativo digital Eldiario.es, la newsletter incorpora un espacio destinado a la participación y la interacción de la audiencia, animando al público a que envíe reflexiones personales sobre su manera de lidiar con el virus.

Tabla 3. Estructura personalizada del boletín de The New York Times

\begin{tabular}{|c|c|c|}
\hline Secciones & Contenido & Ejemplo \\
\hline Introducción & $\begin{array}{l}\text { Se destacan los tres temas más importantes del } \\
\text { día y se ofrecen enlaces específicos en la web } \\
\text { del medio para obtener la información más } \\
\text { actualizada. }\end{array}$ & $\begin{array}{l}\text { - Ya han contraído el coronavirus más de cinco millones de personas } \\
\text { en todo el mundo. Se han confirmado un millón de infecciones } \\
\text { nuevas en menos de dos semanas. } \\
\text { - Continúan las consecuencias económicas en EUA con otros 2,4 } \\
\text { millones de estadounidenses en el paro. } \\
\text { - } \quad \text { El líder de Chechenia fue hospitalizado en Moscú con síntomas de } \\
\text { coronavirus. } \\
\text { - Infórmese de lo último aquí. Puede consultar mapas y hasta un } \\
\text { rastreador para las áreas metropolitanas de EUA. }\end{array}$ \\
\hline Opinión y ciencia & $\begin{array}{l}\text { Texto en profundidad en el que se refleja la opi- } \\
\text { nión del periodista sobre alguno de los datos de } \\
\text { mayor relevancia del día. Estos temas suelen tratar } \\
\text { resultados de investigaciones en los que los epi- } \\
\text { demiólogos y los investigadores ocupan un lugar } \\
\text { predominante. No es de extrañar, por lo tanto, que } \\
\text { conformen las fuentes principales del boletín. } \\
\text { Ejemplos: } \\
\text { Jeffrey Shaman, epidemiólogo de Columbia } \\
\text { Lauren Ancel Meyers, epidemióloga de la Uni- } \\
\text { versity of Texas (Austin). }\end{array}$ & $\begin{array}{l}\text { Sabemos que a principios de marzo la pandemia estaba golpeando } \\
\text { con fuerza los EUA. Sin vacunas, terapias eficaces ni pruebas PCR, la } \\
\text { única forma de combatirla era el confinamiento y el aislamiento social. } \\
\text { Desde la Casa Blanca, los mandatarios políticos dudaron a la hora de } \\
\text { actuar generando un clima de desasosiego e interrupciones. Los datos } \\
\text { sobre el número de víctimas les hicieron reaccionar. } \\
\text { ¿Cuál es el precio que hay que pagar por este retraso? Miles de vidas, } \\
\text { dicen los investigadores. }\end{array}$ \\
\hline Internacional & $\begin{array}{l}\text { Información relacionada con la incidencia de la } \\
\text { pandemia en otros países, principalmente en } \\
\text { China. }\end{array}$ & $\begin{array}{l}\text { Desconcertantes brotes en China. } \\
\text { Puede que se trate de la "segunda ola" que todos temen: Aparecen } \\
\text { nuevos casos de coronavirus en el noreste de China, lo que ha llevado } \\
\text { a imponer muchas de las medidas draconianas vistas en Wuhan hace } \\
\text { unos meses, cuando comenzó la pandemia. } \\
\text { Este brote se concentra en Jilin, una provincia de } 27 \text { millones de habi- } \\
\text { tantes ubicada cerca de la frontera con Rusia y Corea del Norte. Esto es } \\
\text { realmente preocupante, porque muchos de los pacientes no habían } \\
\text { salido de China. Las cifras todavía no son alarmantes. Por el momento } \\
\text { se han reportado } 130 \text { infecciones y dos muertes, pero los expertos } \\
\text { advierten de que la situación podría estallar en cualquier momento. }\end{array}$ \\
\hline Anécdotas & $\begin{array}{l}\text { Ejemplos con situaciones, anécdotas o informa- } \\
\text { ción interesante relacionada con los avances y } \\
\text { gestión de la pandemia. }\end{array}$ & $\begin{array}{l}\text { Un ejemplo de rastreo bien hecho. } \\
\text { El sistema sanitario de EUA probablemente quiera emular al de Pater- } \\
\text { son, una ciudad de clase trabajadora situada en New Jersey. } \\
\text { Este método se centra en un grupo de empleados dedicados a llamar } \\
\text { por teléfono a todas las personas que hayan tenido contacto con } \\
\text { infectados con el fin de explicarles que deben ponerse en cuarentena. } \\
\text { Los rastreadores dicen que se trata más de un arte que de ciencia, debido } \\
\text { a que deben persuadir amablemente a las personas para que revelen de- } \\
\text { talles íntimos de sus vidas. Pero parece que funciona: se ha rastreado con } \\
\text { éxito el } 90 \text { por ciento de los cerca de } 6.000 \text { casos que hay en la ciudad. }\end{array}$ \\
\hline Reaperturas & $\begin{array}{l}\text { Resumen de las principales reaperturas de espa- } \\
\text { cios y movilidad en determinadas localidades. }\end{array}$ & $\begin{array}{l}\text { - Después de dos meses, se reanudan los vuelos domésticos en India. } \\
\text { - Algunos centros comerciales de Bangkok están utilizando robots para } \\
\text { imponer protocolos de enmascaramiento y distanciamiento social. } \\
\text { - A pesar de que en Dinamarca se esperaba un aumento de casos } \\
\text { después de la reapertura hace un mes, los ingresos hospitalarios } \\
\text { han disminuido. } \\
\text { - La primera ministra Jacinda Ardern de Nueva Zelanda aprobó una } \\
\text { semana laboral de cuatro días para reactivar la economía. }\end{array}$ \\
\hline
\end{tabular}




\begin{tabular}{|c|c|c|}
\hline Secciones & Contenido & Ejemplo \\
\hline Recomendaciones & $\begin{array}{l}\text { Lista con principales recomendaciones relacio- } \\
\text { nadas con el ocio. }\end{array}$ & $\begin{array}{l}\text { - Piensa en nuevos pasatiempos. Las ventas de libros de autoayuda } \\
\text { con consejos se han disparado. El concepto D.I.Y. (do it yourself), } \\
\text { "hazlo tú mismo", está presente en multitud de actividades relacio- } \\
\text { nadas con la alimentación, la confección, etc. Probablemente exista } \\
\text { un título para cada tema de interés. } \\
\text { - Visita a tus nietos. Las reuniones al aire libre y con mascarilla son de } \\
\text { las actividades más seguras. Algunos expertos recomiendan man- } \\
\text { tener una distancia de entre } 10 \text { y } 12 \text { metros si los abuelos son muy } \\
\text { mayores o si tienen problemas de salud. }\end{array}$ \\
\hline $\begin{array}{l}\text { Avances } \\
\text { informativos }\end{array}$ & $\begin{array}{l}\text { Lista de informaciones relevantes con un link } \\
\text { directo a la web del medio. Se trata de cuatro o } \\
\text { cinco noticias de enfoques diversos. }\end{array}$ & $\begin{array}{l}\text { - El Departamento de Salud y Servicios Humanos indicó que proporcio- } \\
\text { naría hasta 1,2 mil millones de dólares a la compañía farmacéutica } \\
\text { AstraZeneca para desarrollar una posible vacuna contra el corona- } \\
\text { virus. Es el cuarto acuerdo de investigación conocido hasta el mo- } \\
\text { mento. } \\
\text { - Las pruebas de coronavirus en EUA se han visto obstaculizadas por la } \\
\text { fragmentación del sistema de atención médica. } \\
\text { - Según un estudio, los residentes negros y latinos de los asilos mexi- } \\
\text { canos tienen el doble de probabilidades de sufrir brotes de corona- } \\
\text { virus en comparación con los blancos. } \\
\text { - La columna Scratch del Times ilustra las nuevas realidades a las que se } \\
\text { enfrentan catorce maestros de las escuelas públicas. En ella explican } \\
\text { los desafíos de la educación a distancia durante la pandemia. }\end{array}$ \\
\hline $\begin{array}{l}\text { Interacción - } \\
\text { Participación de la } \\
\text { audiencia }\end{array}$ & $\begin{array}{l}\text { Espacio reservado a la participación de la au- } \\
\text { diencia. Los editores del boletín especializado } \\
\text { animan a su público a enviar pequeñas reflexio- } \\
\text { nes (un párrafo) en las que deben explicar cómo } \\
\text { están lidiando con el confinamiento y con la } \\
\text { situación actual. }\end{array}$ & $\begin{array}{l}\text { Envíanos una respuesta aquí y es posible que la incorporemos en el si- } \\
\text { guiente boletín informativo: } \\
\text { Ejemplo: } \\
\text { Después de semanas confinados, siendo cinco en la familia, podíamos } \\
\text { volvernos más irritables y críticos. Para evitar el ambiente negativo, eti- } \\
\text { quetamos cinco tazas con el nombre de cada persona y las alineamos } \\
\text { en el alféizar de la ventana. Cuando alguien se comportaba amable- } \\
\text { mente, tirábamos una ficha de póquer en la taza de la "Amabilidad". Si } \\
\text { se llenaba, esa persona podía elegir un postre para la familia. De esta } \\
\text { manera, todos se beneficiaban de los actos de bondad de los demás. } \\
\text { - Abigail Nields Hillman, Radnor, Pennsylvania. }\end{array}$ \\
\hline
\end{tabular}

\subsection{Boletín de The Guardian: The week explained}

El diario británico presentaba su newsletter el 18 de marzo de la siguiente manera:

"¿te sientes abrumado por el gran volumen de información sobre el coronavirus? Nuestros periodistas te explicarán los eventos de la semana y te proporcionarán algunos datos en esta situación en constante cambio".

The week explained es un boletín de autor, semanal y gratuito, distribuido cada viernes a las 14:00 h. En las ediciones analizadas la autoría se reparte entre periodistas especializados en las secciones de ciencia y salud del medio. Así, el boletín lo firman profesionales como Hannah Devlin, Ian Sample, Sarah Boseley y Nicola Davis.

A pesar de tratarse de una newsletter semanal, es la más breve de las estudiadas, aunque destaca la personalidad del periodista en la reflexión global sobre los temas más importantes de la pandemia. Son muy habituales los ejemplos en los que se promocionan las voces de los periodistas del medio siguiendo la dinámica del resto de diarios analizados. Se trata de un boletín informativo que presenta ciertos elementos que permiten afirmar que persigue, a su vez, una finalidad estratégica. Sucede esto, por ejemplo, cuando se incorpora, al final de cada boletín, una pestaña resaltada para invitar al usuario a subscribirse al medio.

En lo que respecta al uso de recursos multimedia, predomina el texto y las imágenes. Estas últimas se utilizan, principalmente, como acompañamiento a la información más relevante de la semana. Todas las newsletters incorporan imágenes interactivas que redirigen al usuario al canal de YouTube (Guardian news) del diario.
Según la visión de los expertos, el proceso de captación de lectores pasa por ofrecer contenidos especializados y de mayor calidad. Los boletines tienen el valor de ser canales que muestran una realidad particular a través de la voz de periodistas especializados en un tema concreto 
Tabla 4. Estructura personalizada del boletín de The Guardian

\begin{tabular}{|c|c|c|}
\hline Secciones & Contenido & Ejemplo \\
\hline Introducción & $\begin{array}{l}\text { Una frase que resume lo más destaca- } \\
\text { do de la semana + Introducción de la } \\
\text { periodista. }\end{array}$ & $\begin{array}{l}\text { Atención a la hidroxicloroquina... Suecia en el punto de mira... los casos vuel- } \\
\text { ven a aumentar en Irán. } \\
\text { Bienvenido/a al resumen de esta semana sobre la evolución de la pandemia. } \\
\text { A medida que disminuyen las restricciones en todos los países, los científicos } \\
\text { reflexionan sobre por qué algunos grupos se han visto más afectados que otros } \\
\text { y cuáles son las estrategias más exitosas para combatir el virus. } \\
\text { Suecia en el punto de mira. } \\
\text { La estrategia adoptada por Suecia para hacer frente al coronavirus se ha cali- } \\
\text { ficado como "suave", con aperturas de gimnasios, tiendas y restaurantes y res- } \\
\text { tricciones de viajes no esenciales. Estas medidas contrastan con los estrictos } \\
\text { cierres de países vecinos como Noruega y Dinamarca. } \\
\text { El epidemiólogo sueco Anders Tegnell ha dicho que el país podría haberlo } \\
\text { hecho mejor. En declaraciones a la radio sueca, manifestó que habían muerto } \\
\text { muchas personas a causa de la Covid-19 y que se tendría que haber adoptado } \\
\text { una postura intermedia. }\end{array}$ \\
\hline $\begin{array}{l}\text { Desarrollo de los } \\
\text { temas }\end{array}$ & $\begin{array}{l}\text { Destaca el sello de los profesionales del } \\
\text { medio. El boletín se concibe a modo de } \\
\text { reflexión general sobre los asuntos más } \\
\text { candentes de la actualidad informativa. } \\
\text { Se trata de un desarrollo más extenso de } \\
\text { dos o tres ideas relevantes. }\end{array}$ & $\begin{array}{l}\text { Suecia en el punto de mira. } \\
\text { La hidroxicloroquina sigue siendo el centro de atención. } \\
\text { Preocupaciones por una segunda ola. } \\
\text { Advertencias sobre obesidad y Covid-19. }\end{array}$ \\
\hline $\begin{array}{l}\text { Science Weekly } \\
\text { Podcast }\end{array}$ & $\begin{array}{l}\text { Contenido promocional del medio. Se } \\
\text { enlaza el contenido a la sección especiali- } \\
\text { zada en ciencia de The guardian. Se anun- } \\
\text { cian entrevistas y contenido relacionado } \\
\text { con los estudios científicos sobre la enfer- } \\
\text { medad publicados en la web del medio. }\end{array}$ & $\begin{array}{l}\text { En la edición de esta semana de Science weekly, lan Sample habla con el pro- } \\
\text { fesor Carl Heneghan sobre las incertidumbres con respecto a la predicción de } \\
\text { futuros brotes de Covid-19 y lo que se puede hacer para prevenirlos. }\end{array}$ \\
\hline
\end{tabular}

\subsection{Boletín de Observador: Coronavírus especial}

El boletín del diario portugués presenta una distribución de contenidos muy similar a su edición web y en este caso este formato funciona como un repositorio de las principales noticias del medio. Cumple, por lo tanto, con una función de escaparate informativo, sin aportar ningún grado de innovación en lo que a contenidos se refiere. Es el único medio de los analizados que no presenta una estructura personalizada.

La newsletter es anónima y, desde el punto de vista formal, presenta un diseño a dos columnas con enlaces a las informaciones publicadas en la web. De los diarios analizados es, junto con Eldiario.es, el que incorpora un mayor número de noticias en el boletín, con una media de 28 piezas informativas. Sin embargo, se incluyen como destacados, y para leerlas íntegramente hay que acudir a la página principal del medio. El nivel de interacción y participación con la audiencia es muy limitado en este caso y queda restringido a la posibilidad de hacer click en los destacados para continuar la lectura en la web.

Atendiendo al uso de la multimedialidad, predominan la información textual y las imágenes. Sin embargo, se trata de contenido replicado y no creado específicamente para el boletín. Se corresponde con un modelo de curación automatizada (Guallar et al., 2021a), sin identificación del responsable de la información y sin ningún tipo de aportación periodística.

Por último, en lo que respecta a los contenidos, destacan las noticias sobre la evolución de la pandemia en Portugal. En este sentido, es relevante el predominio de informaciones locales (el caso de un positivo en la guardería en Quarteira, en el ayuntamiento de Loulé; aumento de incidencia por Covid-19 en el municipio de Loures, en el distrito de Lisboa, o la noticia sobre el número de infectados por coronavirus a raíz de la celebración de una fiesta ilegal en Lagos).

Las newsletters especializadas ayudan a hacer un mejor periodismo sobre temas específicos para ciertas audiencias 
Tabla 5. Estructura adaptada del boletín del Observador

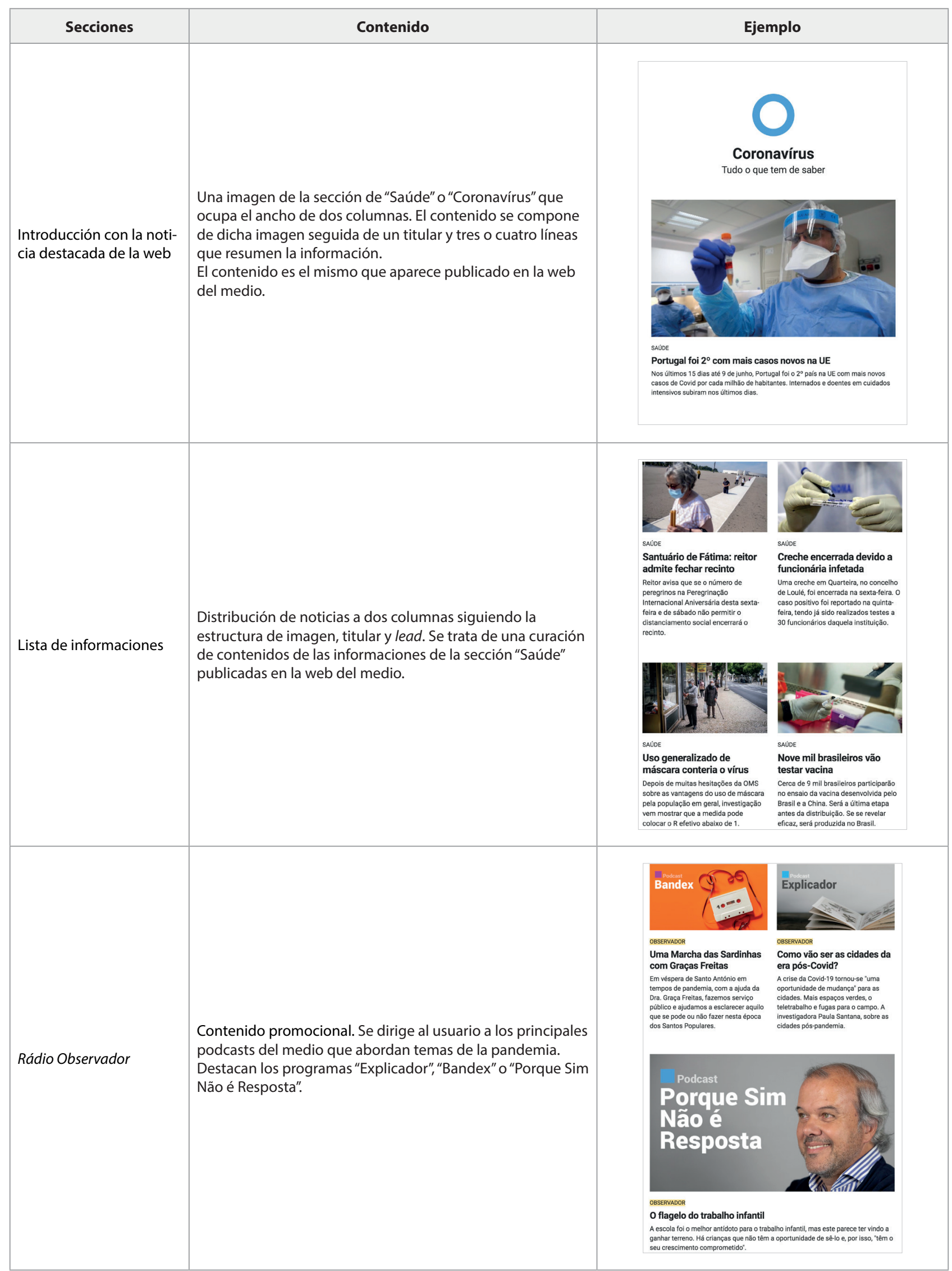




\section{En busca de un modelo de negocio para los medios}

El conjunto de datos extraídos del análisis de contenido se ha complementado con los resultados de las entrevistas realizadas a cinco expertos en el tema investigado: Josep-Lluís Micó, Marius Dragomir, Alfred Hermida, Luís Antonio Santos y Kevin Young.

Los hallazgos de este trabajo indican que las newsletters especializadas en Covid-19 son principalmente informativas, aunque también persiguen un fin estratégico. Esta idea está en estrecha sintonía con las opiniones de los expertos, pues la mitad de los entrevistados considera que los boletines tienen el objetivo de informar, pero buscan también incentivar subscripciones, micropagos, descargas, etc.

Todos los profesionales coinciden que se trata de un formato con fortalezas. Sin embargo, existen discrepancias cuando se valoran como nuevo modelo de negocio. Josep-Lluís Micó considera que las newsletters son un auténtico modelo de negocio para los medios digitales. Según Luís Antonio Santos, es demasiado pronto para dicha afirmación. Los boletines, a juicio de Dragomir, se han convertido en algunos casos en ejemplos de productos periodísticos lucrativos, que generan ingresos. Sin embargo, considera que su principal utilidad reside en la captación de usuarios a las plataformas principales de los medios existentes.

Entre los tipos de ingresos que se generan para asegurar su rentabilidad destacan la publicidad, las suscripciones o el branded

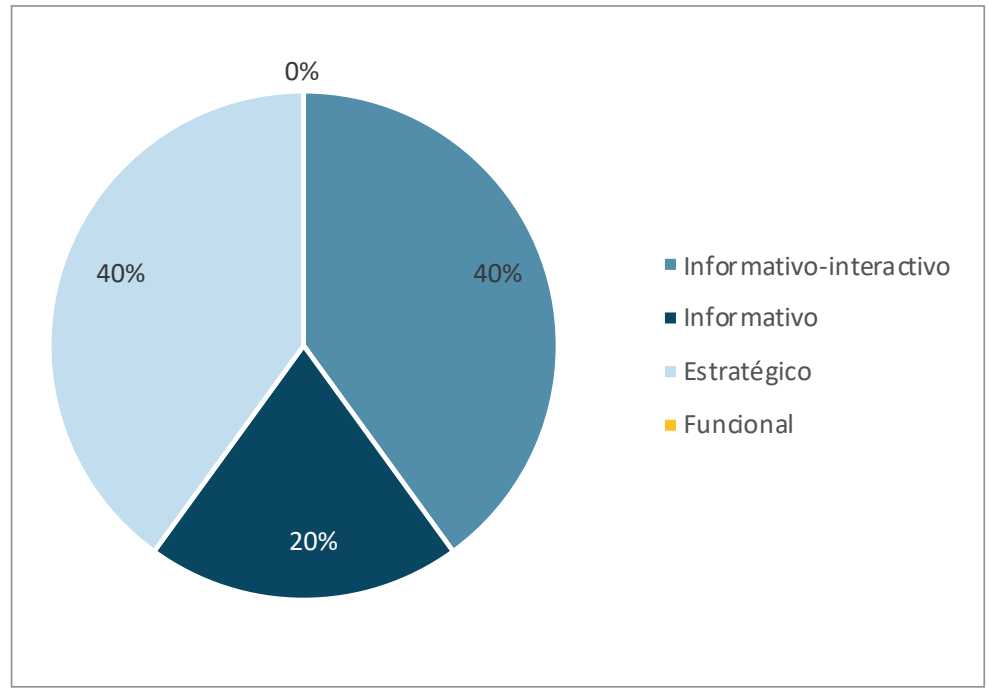

Gráfico 4. Propósito de las newsletters según los expertos content. Sin embargo, todos los entrevistados afirman que son las tarifas de suscripción las que proporcionan mayores fondos. Esta idea también la comparte Kevin Young, director de audiencia de The economist, que sostiene que su periodismo se financia principalmente a través de suscripciones. El boletín sobre Covid-19 de este diario cuenta con tres millones de destinatarios, si bien es cierto que se envía como una edición adicional especial del general The economist this week. Kevin Young explica que en The economist, para captar nuevos lectores y mejorar las cifras de suscripción, se realizan promociones cruzadas del contenido en diferentes plataformas digitales e impresas, además de utilizar las redes sociales, los boletines y las alertas automáticas para ayudar a redirigir a los lectores habituales y captar nueva audiencia.

La posibilidad de un proceso de conversión de lectores a suscriptores a raíz de la necesidad por adquirir información segmentada sobre la epidemia no está clara. Desde los medios no ofrecen datos que ayuden a despejar esta incógnita. La mayor parte de los expertos piensa que habrá una disminución en el número de suscriptores una vez que se supere la crisis del coronavirus. Aunque Micó afirma que no cree que la caída sea muy drástica, porque los precios son razonables, el resto considera que existe esa posibilidad, a menos que -como apunta Antonio Luís Santos-, se puedan reconvertir en boletines más amplios que hagan el seguimiento de pandemias o traten sobre la salud, en general. El interés de la audiencia suele decaer una vez que termina un evento, apunta Dragomir. Sin embargo, como la crisis sanitaria ha sido un acontecimiento realmente masivo en la historia de la humanidad, la gente empezará a interesarse y a leer más sobre temas de salud. Hermida cree que una de las causas por las que pueden decaer los suscriptores de boletines sobre la pandemia está relacionada con la reasignación de ingresos destinados a otras cosas una vez que se recupere la normalidad. Al cambiar la gestión del tiempo disponible cambiarán también las necesidades.

\section{Especialización y personalización como elementos clave para retener suscriptores}

Del análisis realizado se desprende que los contenidos especializados a través de voces expertas en el tema tratado tienen un gran protagonismo. Según la visión de los expertos, el proceso de captación de lectores pasa por ofrecer una mayor calidad y especialización. Los boletines tienen el valor de ser canales que muestran una realidad particular a través de la voz de periodistas expertos en un tema concreto. Según Luís Antonio Santos, conceptos como la calidad o la confianza son claves en este sentido. La personalización, la multimedialidad y la hipertextualidad son, a juicio de los entrevistados, los elementos más importantes a la hora de considerar un boletín. Todos coinciden al afirmar que la personalización de contenidos tiene mucho valor. Kevin Young, por su parte, desde el ámbito profesional, afirma que en los boletines de The economist se integran recursos multimedia, hipertextuales y participativos. La exclusividad en el contenido o las voces expertas pueden, en cierto modo, constituir un factor de innovación, opina el investigador portugués Luís Antonio Santos. Esto es algo que puede analizarse en las newsletters de Eldiario.es, The Guardian o The New York Times. 
Los hallazgos del estudio empírico muestran que los boletines cumplen con estas características. Pese a todo, existen medios como el portugués Observador que se centran en repetir titulares y compartir enlaces más que en experimentar con los recursos que ofrecen las newsletters. Es algo que avanza Dragomir al apuntar que gran parte del contenido publicado en los boletines es reciclado o reutilizado de la web del medio principal. Para explicar esta práctica es necesario analizar el impacto de los boletines en las rutinas periodísticas. Tal y como indica Micó, aunque estos funcionan como plataformas para expresarse o para promocionar el trabajo periodístico, su proceso productivo acarrea más trabajo para los profesionales. Eso explica que, en muchas ocasiones no se considere un producto editorial con identidad personal en el que se conjugan diferentes recursos multimedia e interactivos. Micó aboga por que se usen distintas tecnologías 4.0 como pueden ser, por ejemplo, los datos masivos (big data), la realidad virtual o la realidad aumentada. Para Dragomir, la interactividad puede ser un aspecto determinante, tanto en lo que se refiere al formato como en lo que tiene que ver con la participación de la audiencia. Las plataformas de distribución también cumplen un papel relevante para que los usuarios localicen fácilmente los temas que les interesan.

Los boletines especializados, como los que abordan el tema de la Covid, cuentan con diversos beneficios. Por una parte, Micó destaca la personalización y la posibilidad de integrar a la audiencia que se articula alrededor de los medios. Dragomir y Luís Antonio Santos opinan que el acceso a la cobertura de un tema de interés es la mayor cualidad que presentan estas newsletters. Para los medios, afirma, la posibilidad de acceder a una audiencia dirigida es muy interesante. Aspecto con el que concuerda Hermida, para quien llegar a una audiencia de nicho interesada en un tema específico constituye una de sus principales ventajas. A la larga, si el boletín es de calidad, la audiencia será fiel. Para el responsable de medios sociales y audiencias de The economist, las newsletters especializadas ayudan a hacer un mejor periodismo sobre temas específicos para ciertas audiencias.

Los entrevistados coinciden al destacar la importancia de un perfil periodístico dedicado a la elaboración de newsletters personalizadas y especializadas en un área tan específica como la del coronavirus. Para Micó los boletines son el medio idóneo para ofrecer información sobre la pandemia del coronavirus porque permiten condensar el contenido más relevante en un espacio reducido y hacerlo, además, de manera instantánea. Audiencia asegurada y relación íntima con los usuarios son los valores destacados por Dragomir para hablar de las posibilidades de las newsletters especializadas en Covid-19.

\section{Consideraciones finales}

Este trabajo muestra el interés de los medios digitales por adaptar y organizar los contenidos relacionados con la pandemia a nuevos formatos de curación de contenidos como las newsletters. Recuperando el 01 de este trabajo, se puede afirmar que la crisis sanitaria y el contexto de saturación informativa han favorecido la emergencia de los boletines especializados en coronavirus a partir del 2 de marzo como un canal a partir del cual los medios pueden ejercer su función como servicio público. Se demuestra, además, la utilidad de este formato para la curación de contenidos.

Siguiendo el 02 , el estudio permite deducir que los boletines analizados tienden a la especialización y a la personalización de contenidos, dos de los aspectos más valorados por los expertos al destacar las fortalezas de esta narrativa. La especialización viene determinada por el gran predominio de fuentes expertas principalmente en las áreas de salud y ciencia. Este aspecto es especialmente relevante debido a que existe un patrón coincidente en las secciones de los boletines reservando un espacio destacado para las noticias con estudios científicos, avances o hallazgos de investigadores. Sin embargo, aunque no se han localizado ejemplos claros de personalización de contenidos, los boletines son canales idóneos para explotar dicha característica.

Todos los boletines estudiados, excepto el del medio portugués Observador, persiguen una finalidad informativa y/o estratégica, con el fin de incentivar subscripciones, visitas a la web, micropagos, descargas, etc. En línea con el O3 constatamos, por lo tanto, que las newsletters especializadas en Covid-19 tienen un propósito eminentemente informativo, pero también se observan indicios de su utilidad para la captación y retención de usuarios. Este aspecto se pone de manifiesto en el protagonismo de secciones dedicadas a la autopromoción de contenidos cuyos casos más representativos son los de The guardian (Science weekly podcast) y Observador (Rádio Observador). También existe otro propósito funcional 
orientado a ofrecer un servicio a la comunidad a modo de guía de recursos que facilita el acceso a datos oficiales sobre la pandemia. Es el caso de Eldiario.es con la sección Funcional: las respuestas que tenemos con información de servicios (teléfonos del Ministerio de Sanidad, WhatsApp de Sanidad) o la guía de la Escuela de Medicina de la Harvard University.

Siguiendo el O4, podemos determinar que el principal enfoque de las newsletters especializadas en coronavirus es científico, a partir de las voces de epidemiólogos, investigadores y/o periodistas especializados. Además, destacan las actualizaciones de datos sobre nuevos casos o el nivel de incidencia de la enfermedad.

Por último, respondiendo al 05, este estudio permite identificar una estructura específica de los boletines especializados con respecto al formato y a la organización de contenidos. Del análisis realizado se concluye que las principales características son las siguientes:

- Estructura personalizada: los boletines se organizan alrededor de una serie de bloques temáticos (mínimo tres y máximo ocho) priorizando las secciones de salud, investigación e internacional.

- De autor: las newsletters son, en general, de autor. Pese a que no siempre las firma la misma persona (excepto la de Eldiario.es), la tendencia general es que los autores sean periodistas especializados en las secciones de Ciencia y Salud de los respectivos diarios analizados (ej: The guardian / The New York Times). Con relación a esto, se confirma la tendencia apuntada en estudios previos (Guallar et al., 2021a) sobre la prevalencia de la curación intelectual en detrimento de la automatizada. Del análisis se concluye que solamente el diario portugués opta por un modelo de automatización de contenidos en el que no está presente la identidad del periodista y en donde no se aplica ninguna técnica de sense making.

- Canal de autopromoción: todos los medios utilizan sus boletines para redirigir a la audiencia a sus webs principales o para promocionar el trabajo de determinados periodistas.

- Participación e interacción de la audiencia: los boletines son excelentes medios para promover la participación y la interacción de los usuarios. Eldiario.es incluye en su newsletter un espacio a modo de ágora en el que los lectores pueden aportar sus experiencias personales y/o sus opiniones sobre la gestión de la pandemia.

- Redacción informal y personalidad del periodista: las newsletters especializadas en Covid-19 destacan por usar un tono informal, próximo a los lectores. Es importante el sello del profesional y las alusiones directas al lector.

- Formato hipertextual: el modelo más común se centra en el uso de texto y/ o imágenes y, en ocasiones, se incorporan elementos gráficos como los emoticonos (Eldiario.es) o mapas (The New York Times). La hipertextualidad es la característica que está más presente en esta narrativa.

Las newsletters por correo electrónico no constituyen la gran solución para los medios en un contexto de saturación y sobreabundancia informativa, pero sí una oportunidad. Los boletines están siendo un canal importante para retener a la audiencia y promover su participación y está demostrado que existen ejemplos de este formato que generan ingresos. Además, a juicio de las opiniones de los expertos, se consideran idóneos para transmitir información sobre la pandemia. Se erigen en la actualidad como una de las herramientas más importantes disponibles para los editores que sirven para construir hábitos y para atraer clientes a través de la suscripción o la publicidad.

Los editores de medios tendrán un reto en los próximos años en lo que se refiere a la gestión y producción de newsletters. Los boletines conllevan una cantidad de opciones para los consumidores, que demandan contenido distintivo, de calidad y específico. Los resultados muestran que las newsletters son un producto que permite que los usuarios, a través de un tono informal y en ocasiones humorístico, puedan estar en contacto con periodistas especializados en una determinada área.

Si bien esta narrativa continúa evolucionando con el paso del tiempo, las características de las más exitosas (simplicidad, diseño, curación y serendipia) encuentran sus paralelos en otras formas de producción periodística y serán cada vez más valiosas en los próximos años en un mundo dominado por la abundancia informativa.

Por último, conviene destacar los logros, limitaciones y futuras líneas de investigación de este estudio. Respecto a su valor diferencial, se trata del primer trabajo que analiza e identifica las características principales de las newsletters especializadas en Covid-19 en un conjunto de medios digitales de referencia. Supone, por lo tanto, un punto de partida para futuras investigaciones relacionadas con esta área y ofrece una primera aproximación sobre la estructuración de contenidos de las newsletters que siguen el modelo de curación intelectual. Además, se sitúan los retos y desafíos de un formato en auge.

En cuanto a las limitaciones, se debe puntualizar que se trata de un análisis exploratorio a partir de una muestra reducida que no representa la realidad global del fenómeno analizado. Además, el hecho de que no se obtuviera ninguna respuesta de los responsables editoriales de los boletines que componen el objeto de estudio ha supuesto una dificultad añadida. En este sentido, se abren futuras líneas de investigación que podrían centrarse en abordar este tema de manera sistematizada aplicando, por ejemplo, el sistema de análisis CAS (curation analysis system) propuesto por Guallar et al. (2021b) con el fin de ayudar a comprender las potencialidades de la curación de contenidos en el periodismo. Además, sería interesante realizar una base de datos sobre la incidencia de newsletters especializadas en los medios internacionales profundizando en las temáticas, fuentes, autoría y tipos de curación. 


\section{Referencias}

Apezarena, José (2005). Periodismo al oído: los confidenciales: de las cartas manuscritas a Internet. Barcelona: Random House Mondadori. ISBN: 8483066386

Assmann, Karin; Diakopoulos, Nicholas (2017). “Negotiating change: Audience engagement editors as newsroom intermediaries". In: International symposium on online journalism (ISOJ), pp. 25-44.

https://goo.gl/HeUjha

Bosch, Josep-Lluís; Torrente, Diego (1993). Encuestas telefónicas y por correo. Madrid: Centro de Investigaciones Sociológicas. ISBN: 9788474761849

Broussard, Shorna; Floress, Kristin (2010). Are newsletters effective? Asssessing their role as a communication tool. Purdue Extension.

https://mdc.itap.purdue.edu/item.asp?itemID=17769

Bucy, Erik P. (2004). "Interactivity in society: Locating an elusive concept". The information society, v. 20, n. 5, pp. 373383.

https://doi.org/10.1080/01972240490508063

Casero-Ripollés, Andreu (2020). "Impact of Covid-19 on the media system. Communicative and democratic consequences of news consumption during the outbreak". El profesional de la información, v. 29, n. 2.

https://doi.org/10.3145/epi.2020.mar.23

Comscore (2020). "Coronavirus pandemic and online behavioural shifts". Comscore, 23 March. https://cutt.ly/ykiTCEa

Díaz-Arias, Rafael (2015). “Curaduría periodística, una forma de reconstruir el espacio público". Estudios sobre el mensaje periodístico, v. 21, n. 80.

https://revistas.ucm.es/index.php/ESMP/article/view/51129

Fagerlund, Charlotte (2016). Back to the future-email newsletters as a digital channel for journalism. Londres: Polis. https://www.yumpu.com/en/document/view/55025101/back-to-the-future-email-newsletters-as-a-digital-channel-forjournalism

FIPP (2019). Global digital subscription snapshot. November 2019.

https://www.fipp.com/news/global-digital-subscriptions-snapshot-november-2019

García-Avilés, José-Alberto (2021). "Review article: Journalism innovation research, a diverse and flourishing field (2000-2020)". Profesional de la información, v. 30, n. 1.

https://doi.org/10.3145/epi.2021.ene.10

Guallar, Javier; Anton, Laura; Pedraza-Jiménez, Rafael; Pérez-Montoro, Mario (2021a). “Curación de noticias en el correo electrónico: análisis de newsletters periodísticas españolas". Revista latina de comunicación social, v. 79, pp. 47-64. https://doi.org/10.4185/RLCS-2020-1488

Guallar, Javier; Codina, Lluís (2018). “Journalistic content curation and news librarianship: Differential characteristics and necessary convergence". El profesional de la información, v. 27, n. 4, pp. 778-791.

https://doi.org/10.3145/epi.2018.jul.07

Guallar, Javier; Pedraza-Jiménez, Rafael; Pérez-Montoro, Mario; Anton, Laura (2021b). “Curación de contenidos en periodismo. Indicadores y buenas prácticas". Revista española de documentación científica, v. 44, n. 2.

https://doi.org/10.3989/redc.2021.2.1742

Ha, Anthony (2016). "The New York Times invests in theSkimm". TechCrunch, 2 September. https://techcrunch.com/2016/09/26/nyt-backs-theskimm

Hendrickx, Jonathan; Donders, Karen; Picone, Ike (2020). "Innovating journalism by going back in time? The curious case of newsletters as a news source in Belgium". In: Vázquez-Herrero, Jorge; Direito-Rebollal, Sabela; Silva-Rodríguez, Alba; López-García, Xosé (2020). Journalistic metamorphosis: Media transformation in the digital age. Suiza: Springer, pp. 57-68. ISBN: 9783030363154 https://doi.org/10.1007/978-3-030-36315-4_5

Jack, Andrew (2016). Editorial email newsletters. The medium is not the only message. Reuters Institute for the Study of Journalism.

https://reutersinstitute.politics.ox.ac.uk/our-research/editorial-email-newsletters-medium-not-only-message

Krippendorff, Klaus (2002). Metodología de análisis de contenido. Teoría y práctica. Barcelona: Paidós. ISBN: 847509 6271 
Kumar, Ashish; Salo, Jari (2016). "Effects of link placements in email newsletters on their click-through rate". Journal of marketing communications, v. 24, n. 5, pp. 535-548.

https://doi.org/10.1080/13527266.2016.1147485

Lázaro-Rodríguez, Pedro; Herrera-Viedma, Enrique (2020). "Noticias sobre Covid-19 y 2019-nCoV en medios de comunicación de España: el papel de los medios digitales en tiempos de confinamiento". El profesional de la información, v. 29, n. 3.

https://doi.org/10.3145/epi.2020.may.02

López-Rico, Carmen-María; González-Esteban, José-Luis; Hernández-Martínez, Alberto (2020). “Consumo de información en redes sociales durante la crisis de la Covid-19 en España”. Revista de comunicación y salud, v. 10, n. 2, pp. 461481. https://doi.org/10.35669/rcys.2020.10(2).461-481

McClaran, Sharon-Nicole (2017). Agenda setting in your inbox: The effect of daily email newsletters. Doctoral thesis. Florida: Florida State University. https://fsu.digital.flvc.org/islandora/object/fsu\%3A507705

Mitchelstein, Eugenia; Boczkowski, Pablo J. (2010). “Online news consumption research: An assessment of past work and an agenda for the future". New media \& society, v. 12, n. 7, pp. 1085-1102. https://doi.org/10.1177/1461444809350193

Montaña-Blasco, Mireia; Ollé, Candela; Lavilla-Raso, Montse (2020). "Impacto de la pandemia de Covid-19 en el consumo de medios en España". Revista latina de comunicación social, n. 78, pp. 155-167.

https://doi.org/10.4185/RLCS-2020-1472

Moreno-Castro, Carolina; Vengut-Climent, Empar; Cano-Orón, Lorena; Mendoza-Poudereux, Isabel (2020). “Estudio exploratorio de los bulos difundidos por WhatsApp en España para prevenir o curar la Covid-19". Gaceta sanitaria, first online.

https://doi.org/10.1016/j.gaceta.2020.07.008

Newman, Nic; Fletcher, Richard; Levy, David A. L.; Nielsen, Rasmus-Kleis (2016). Digital news report 2016. Oxford: Reuters Institute for the Study of Journalism.

https://reutersinstitute.politics.ox.ac.uk/sites/default/files/research/files/Digital\%2520News\%2520Report\%25202016.pdf

Newman, Nic; Fletcher, Richard; Schulz, Anne; Andi, Simge; Nielsen, Rasmus-Kleis (2020a). Digital news report 2020. Oxford: Reuters Institute for the Study of Journalism.

https://reutersinstitute.politics.ox.ac.uk/sites/default/files/2020-06/DNR_2020_FINAL.pdf

Nielsen, Rasmus-Kleis; Fletcher, Richard; Kalogeropoulos, Antonio; Simon, Felix (2020b). Communications in the coronavirus crisis: lessons for the second wave. Oxford: Reuters Institute for the Study of Journalism.

https://reutersinstitute.politics.ox.ac.uk/communications-coronavirus-crisis-lessons-second-wave

Núñez, Vilma (2014) “El newsletter. ¿Qué es y cuáles son sus utilidades en marketing?”. Vilma Nuñez.

https://vilmanunez.com/que-es-newsletter

Ramírez, María (2020). "El boletín". Eldiario.es, 19 junio.

https://www.eldiario.es/opinion/zona-critica/el-boletin_129_6064202.html

Rojas-Torrijos, José-Luís; González-Alba, José-Antonio (2018). “La newsletter como producto periodístico en la búsqueda de nuevos lectores. Estudio de boletines de noticias de El país, El español y El independiente". AdComunica, n. 15, pp. 165-195.

http://www.adcomunicarevista.com/ojs/index.php/adcomunica/article/view/414/384

Santos, Clara-Almeida; Peixinho, Ana-Teresa (2017). "Newsletters and the return of epistolarity in digital media. The case of the Portuguese online newspaper Observador". Digital journalism, v. 5, n. 6, pp. 774-790.

https://doi.org/10.1080/21670811.2016.1196591

Santos-Silva, Dora; Granado, António (2019). “Old formats, new combinations: How newsletters represent innovation and blurring boundaries in digital journalism". In: ECREA Journalism studies conference 2019, Vienna, Austria. https://novaresearch.unl.pt/en/publications/old-formats-new-combinations-how-newsletters-represent-innovation

Trilling, Damian; Schoenbach, Klaus (2015). "Investigating people's news diets: How online news users use offline news". The European journal of communication research, v. 40, n. 1, pp. 67-91.

https://doi.org/10.1515/commun-2014-0028 